\title{
An Empirical Methodology to Estimate a Local Yield Stress in Work-hardened Surface Layers
}

\author{
by J.P. Nobre, A.M. Dias and M. Kornmeier
}

\begin{abstract}
A methodology is proposed for estimating the local yield stress in work-hardened surface layers. It is based on the concept of in-depth normalized variation of hardness and $x$-ray diffraction peak width, both of which measure the strain-hardening attained by the materials' surface-treated layers due to, for example, shot-peening. Its principle is directly founded on the classical hardness theory. To study the evolution of those values with plastic deformation, specimens of five steels with different mechanical properties were subjected to interrupted tensile tests. The tests were performed at successive increments of plastic strain, until fracture occurred. The specimens were loaded and unloaded in increments of about $2 \%$ true strain. After each plastic strain increment, hardness and diffraction peak width were measured. It was observed that the variations of diffraction peak width and hardness are related to the material's strain-hardening, and their normalized variations can be considered proportional to the normalized variation of the material's yield stress. Thus, where the yield stress of the bulk material, its hardness or a characteristic diffraction peak width value, and their relative variations along the hardened layers, are known, an empirical expression could be used to estimate the local yield stress as a function of the treated depth.
\end{abstract}

KEY WORDS-Mechanical behavior, shot-peening, yield strength, strain-hardening, micro-hardness, x-ray diffraction

\section{Introduction}

Knowledge of local yield strength in a material's hardened layers, due to mechanical surface treatments, such as for example shot-peening, is of great relevance in several areas of mechanical engineering science. ${ }^{1}$ Problems of fatigue, contact fatigue or wear need valid behavior laws for surfacetreated material layers. That knowledge is also required, for example, in the study of the so-called plasticity effect on the results of the incremental hole-drilling technique for residual stress measurements ${ }^{2 \sim 4}$ or for numerical prediction models of residual stress relaxation due to dynamic loading. 5,6

Mechanical surface treatments, such as shot-peening, use local plastic deformation (not uniform plastic deformation) as a way of introducing compressive residual stresses, and so improve the useful life of mechanical components. Accord-

J.P. Nobre (joao.nobre@dem.uc.pt) is an Auxiliary Professor and A.M. Dias is a Full Professor, Mechanical Engineering Department, University of Coimbra, P-3030, Coimbra, Portugal. Dr. M. Kornmeier is currently working at the European Patent Office, Munich, Germany. ing to Wohlfahrt, ${ }^{7}$ that deformation is due to two main effects: a direct plastic elongation at the surface, induced by the tangential forces (hamming effect), which implies maximum compressive residual stress at the surface; and a plastic strain in the sub-layers, induced by the Hertz pressure (Hertz effect), which implies maximum compressive residual stresses within the material, below the surface. Furthermore, heat dissipation could imply plastic compression and the appearance of tensile residual stresses at the surface. Depending on the mechanical characteristics of the materials, the combination of these effects produces, by overlapping, the final in-depth compressive residual stress profile.

Shot-peened layers are subjected to cyclic plastic deformation, induced by the impacts of the peening medium, at high plastic strain rates. Therefore, the elasto-plastic behavior of the material near the surface can be completely different from that found for the bulk material. ${ }^{8,9}$ Guechichi $^{10}$ proposed an analytical model, comparing the case of shot-peening to a simple cyclic loading process, as a means of predicting the residual stresses induced by the different treatment conditions. In this model, two different in-depth regions were considered. Close to the surface, there is a region called the "accommodated zone", characterized by the saturated value of the residual stresses related to the material's cyclic elastic limit. In this region, the material is subjected to repeated deformation, and the material can therefore be subjected to cyclic hardening or softening. As a result, the strain hardening behavior should be modified. Below this region, there is a region called the "adapted zone", characterized by the fast decline of the residual stresses. In this region the material is taken to be subjected to monotonic plastic deformation.

$\mathrm{X}$-rays make it possible to study the in-depth variation of diffraction peak width. This value is related to the square root of the mean quadratic value of the distortion of the crystalline lattice $\left\langle\varepsilon^{2}\right\rangle^{1 / 2}$, which is directly proportional to the microscopic residual stress (third order). ${ }^{11,12}$ Using scanning electronic microscopy, Hakimi ${ }^{13}$ analyzed the in-depth variation of the dislocation configuration in AFNOR 35CD4 shotpeened steel. Hakimi found that, close to the surface, the dislocations are small, fine and in forest. As the depth increases, the dislocations tend to be longer, rectilinear and fewer. $\mathrm{He}$ also observed that the in-depth dislocation density varied according to the variation of $x$-ray diffraction peak width, i.e., the higher the diffraction peak width, the higher the dislocation density. Micro-hardness measurements made along the cross-section of shot-peened specimens are an equally efficient way of characterizing the mechanical behavior of their

Original manuscript submitted: September 27, 2002.

Final manuscript received: June 6, 2003.

DOI: $10.1177 / 0014485104039755$ 
surface layers, since hardness is a direct measure of the material's strength and can be related to its yield strength. ${ }^{14}$

Several techniques have been proposed for evaluating the mechanical properties of material surfaces. $5,6,8,15$ Desvignes ${ }^{8}$ determined the yield strength of AFNOR 35CD4 shot-peened steel as a function of the treated depth, based on the elasto-plastic analysis of residual stress relaxation during fatigue tests, using the elasto-plastic calculation method of Zarka and Casier. ${ }^{16} \mathrm{Cao}^{9}$ used the in-depth distribution of $\mathrm{x}$ ray diffraction peak width, obtained experimentally throughout the shot-peened surface layers, to evaluate the mechanical properties of those layers. Cao and Castex ${ }^{15}$ used indepth $\mathrm{x}$-ray diffraction peak width measurements to determine the stress-strain relationship of shot-peened surface layers. Batista and co-workers ${ }^{6,17}$ proposed another method for evaluating the mechanical properties of surface-treated steels (shot-peening, nitriding and carbonitriding treatments), based on four-point bending tests, using the $\mathrm{x}$-ray diffraction $\sin ^{2} \psi$ method for stress determination and electric extensometers for strain determination. Virmoux et al. ${ }^{5}$, however, used another procedure to characterize the mechanical properties of the surface layers of the steel AFNOR Z100CD17 treated by laser shock, based on the analysis of quasi-static spherical indentations, comparing experimental in-depth indentations profiles (characterized by the radius and depth), using different loads, with those obtained by finite element simulation. This method is based on the classical hardness theory of Tabor ${ }^{14}$ and the elasto-plastic indentation models of Johnson ${ }^{18}$ and Studman et al. ${ }^{19}$ Other authors use nanoindentation measurements and compressive tests as a way to find the yield strength of specimens subjected to thermochemical surface treatments (e.g., cementation). ${ }^{20}$ A new approach for this problem is described below, with special reference to the local in-depth yield strength estimation in the "adapted region" of the work-hardened surface layers.

Due to the complex and limited application of the methods and techniques described above, it was decided to study a new methodology for local yield strength estimation in work-hardened surface layers by using micro-hardness indentations. The proposed methodology, based on the classical hardness theory, ${ }^{14}$ uses the new concept of in-depth normalized hardness variation. The same results can be achieved using $\mathrm{x}$-ray diffraction peak width values. For this, a calibration procedure was conducted. This was based on the study and analysis of how micro-hardness indentations and $\mathrm{x}$-ray diffraction peak width values evolve with the plastic strain imposed during tensile tests. Tensile tests were carried out at successive plastic strain increments until fracture. After each plastic strain increment of about $2 \%$, samples were unloaded and hardness and diffraction peak width were measured. This procedure provided the material's stress-strain curve and, therefore, the relation between the variation of hardness and diffraction peak width and the variation of the yield strength due to the strain-hardening of the material. To verify the practical applicability of the proposed method, the case of shot-peening treatment was selected. A uniform shotpeening treatment was applied to five steels with different mechanical properties. For all specimens, it was found that both hardness and diffraction peak width values diminished steadily from the surface to the interior, where the values in the bulk material were registered. The relative variations of these quantities were then compared to those obtained in the tensile tests, which finally allowed the estimation of the local yield stress in the shot-peened surface layers.

\section{Description of the Proposed Method}

According to Tabor, ${ }^{14}$ "a convenient method of measuring the elastic limit of a material is to determine its hardness using a pyramidal indenter possessing a large apex angle, as in the Vickers test." His theory on the hardness of metals is founded on experimental evidence. He observed that when a metal is subjected to high cold working, i.e., without capacity for subsequent work hardening, plastic flow begins when the mean contact pressure is given by:

$$
p_{m}=c \sigma_{y}
$$

where $c$ is a constant of about 3 and $\sigma y$ can be considered as a "representative yield stress". ${ }^{14}$ Based on this theory, Tabor formulated an equation to estimate the ultimate strength of a material. Several attempts have been made to estimate the $0.2 \%$ offset yield strength. George et al. ${ }^{21}$ proposed a method using the Rockwell hardness data. Using Vickers and Meyer hardness, Cahoon et al. ${ }^{22}$ found an empirical equation that allows the calculation of the yield strength, without needing to know its stress-strain curve, given by:

$$
\sigma_{y 0,2}=\frac{H V}{3}-(0.1)^{m-2} .
$$

In this equation, $\sigma_{y 0,2}$ is the yield strength, $H V$ is the Vickers hardness and $m$ is the Meyer exponent (the strain hardening coefficient $n$ can be related to this exponent by $n=m$ $-2){ }^{14}$ They showed the equation's validity for a $65 \mathrm{~S}$ aluminum alloy and 1040 steel, subjected to various amounts of cold working. For a given Meyer exponent $m$, this empirical equation clearly shows proportionality between $\sigma_{y}$ and $H V$. For a perfectly plastic material, Cahoon's equation is reduced to Tabor's equation, which allows the relationship between the mean contact pressure and a representative yield strength obtained in a tension or compression test. Consequently, if hardness varies to a certain degree, there should be a corresponding variation in yield strength.

Thus, based on the proportionality between hardness and yield strength stated in Tabor's and Cahoon's equations, the increase of the local yield strength $\left(\Delta \sigma_{y}\right)$, relative to the yield strength of the bulk material $\left(\sigma_{y, 0}\right)$, can be easily estimated based on the local increase of hardness ( $\triangle H V$ ), relative to the hardness of the bulk material $\left(H V_{y, 0}\right)$, using the following formula:

$$
\frac{\Delta \sigma_{y}}{\sigma_{y, 0}}=\frac{\Delta H V}{H V_{y, 0}}
$$

If it were possible to formulate some hypothesis, a similar expression could be theoretically deduced when hardness or $x$-ray diffraction peak width are used. From previous works, ${ }^{5,6}$ where the hardness was considered to vary with the plastic strain in accordance with a potential law, similar to the true stress-strain relationship founded in tensile tests, it is possible to consider that both hardness $(H V)$ and diffraction peak width $(H W V)$ might vary with the plastic strain $\left(\varepsilon_{p}\right)$ according to the following expressions:

$$
\begin{aligned}
& H V=H V_{y, 0}+K_{H V} \varepsilon_{p}^{n_{H V}} \\
& H W V=H W V_{y, 0}+K_{H W V} \varepsilon_{p}^{n_{H W V}} .
\end{aligned}
$$


Here, $n_{H V}$ and $n_{H W V}$ are strain-hardening exponents and $K_{H V}$ and $K_{H W V}$ are strength coefficients, corresponding to hardness-strain and diffraction peak width-strain relationships respectively, identical to the strength coefficient presented in well-known true stress-plastic strain relationships, obtained during standard tensile tests, as, for example, $K_{y}$ in the following equation: ${ }^{23}$

$$
\sigma_{y}=\sigma_{y, 0}+K_{y} \varepsilon_{p}^{n} .
$$

This way, it is possible to write

$$
\begin{aligned}
& \sigma_{y}-\sigma_{y, 0}=K_{y}\left(\frac{H V-H V_{y, 0}}{K_{H V}}\right)^{n / n_{H V}} \\
& \sigma_{y}-\sigma_{y, 0}=K_{y}\left(\frac{H W V-H W V_{y, 0}}{K_{H W V}}\right)^{n / n_{H W V}} .
\end{aligned}
$$

Since all exponents $n, n_{H V}$ and $n_{H W V}$ represent the material's strain hardening property, then $n / n_{H V} \approx 1$, $n / n_{H W V} \approx 1$, and the yield stress consequently varies linearly with the hardness or diffraction peak width, with the variation of these quantities itself being a measure of the material's strain hardening capacity. Thus, using bulk material reference values for normalization proposes, the following incremental relation can be written as:

$$
\frac{\Delta \sigma_{y}}{\sigma_{y, 0}}=\gamma \frac{\Delta H}{H_{y, 0}}
$$

where the letter $H$ can correspond to hardness ( $H V$ ) or diffraction peak width ( $H W V), \sigma_{y, 0}$ and $H_{y, 0}$ correspond to the yield stress and hardness or diffraction peak width of the bulk material, respectively, and $\gamma$ is a constant (scale factor) given by:

$$
\gamma=\frac{K_{y}}{K_{H}} \frac{H_{y, 0}}{\sigma_{y, 0}} .
$$

The deduced eq (7) is the basis of the proposed measurement method and relates the linearity between relative increments of hardness (diffraction peak width) and yield stress. That equation can be written in a very convenient form, allowing the yield stress to be estimated, for each level of plastic deformation, in terms of the normalized variation of hardness or diffraction peak width, as follows:

$$
\sigma_{y}=\sigma_{y, 0}\left(1+\gamma \frac{\Delta H}{H_{y, 0}}\right) .
$$

The difference between eqs ( 3 ) and (7) is the appearance of the constant $\gamma$ in the latter. The experimental study presented below was conducted to verify the validity of the linearity hypothesis and the applicability of those equations for local yield strength estimation in work-hardened surface layers. The dependency of the constant $\gamma$ according to the materials used in this study is also analyzed.

\section{Materials and Experimental Procedure}

The experimental study was divided into two parts using five steels with different mechanical properties. In the first part, in order to verify the hypothesis suggested above and the validity of the deduced equations, a series of interrupted tensile tests was performed. These tests allowed the study and analysis of hardness variation and $\mathrm{x}$-ray diffraction peak width variation with plastic strain. In a second phase, selecting the case of the shot-peening treatment, the method described above was applied to determine local yield stress as a function of depth, in work-hardened surface layers. This procedure was carried out, comparing the results of the normalized variation of the hardness and the diffraction peak width determined in those layers.

Table 1 shows mechanical properties and chemical composition of the materials used, listed by yield strength, in increasing order.

Two types of specimen were machined from each asreceived plate. For tensile tests, proportional specimens, according to ASTM E 8, with rectangular cross-sectional areas, were used. For shot-peening treatment, specimens were machined in plane pieces, $12 \mathrm{~mm}$ thick. All specimens, after grinding, were subjected to an electrolytic polishing to remove the layer affected by the machining. This procedure was controlled by means of $\mathrm{x}$-ray diffraction, analyzing the evolution of diffraction peak width with the depth of the removed material surface layer. It was observed that, after a certain depth, the value of the diffraction peak width remained almost constant. The established mean value was considered to be the reference value of the bulk material. In the case of tensile specimens, to obtain homogeneous and plane surfaces, the electrolytic polishing was carried out in an electrolyte bath agitated in a rotational movement imposed by a magnetic field, to allow the gradual and homogeneous removal of material from the specimen surfaces. As a mean value, about $200 \mu \mathrm{m}$ of material was removed from each specimen surface. After this prior treatment, the specimens were subjected to axial tensile tests. The specimens were loaded and unloaded in increments of about $2 \%$ true total strain. After each strain increment, the specimens were subjected to hardness tests and $\mathrm{x}$-ray diffraction. This procedure was carried out until the maximum load was attained. After this point, specimens were tensioned until fracture. Although the region from the beginning of the necking zone and the fracture point could give more information, this was not measured due to the difficulty in taking hardness and diffraction peak width measurements in that region. The final cross-section areas of the specimens were measured using optical microscopy and the final hardness and x-ray measurements were taken.

Theoretically, due to the geometric similarity observed in Vickers hardness indentation, on a macroscopic scale, true hardness is almost independent of the load applied and is considered to be a constant of the material. However, on a microscopic scale, due to so-called indentation size effect (ISE), apparent hardness can vary with the indenter size, the depth of the indentation or the test load applied. ${ }^{24,25}$ Generally, depending on the indenter size and indented material, the apparent hardness value decreases asymptotically with increasing load, until true hardness is attained, and that variation ceases. This is why, in the tensile tests specimens, hardness indentations were made using two loads corresponding to 100 and $300 \mathrm{~g}$. In general, it was found that hardness values corresponding to a load of $100 \mathrm{~g}$ are slightly higher than for those of $300 \mathrm{~g}$. However, the methodology proposed in this work uses normalized hardness variation values which avoid that difference in the final results when one or other load is used.

Shot-peening specimens were treated using identical parameters, shown in Table 2. To study the in-depth evolution 


\begin{tabular}{|c|c|c|c|c|c|c|c|c|c|c|c|}
\hline \multirow{2}{*}{$\begin{array}{l}\text { Material } \\
\text { Nr.-AISI }\end{array}$} & \multirow{2}{*}{$\begin{array}{c}\sigma_{y 0.2} \\
(\mathrm{MPa})\end{array}$} & \multirow{2}{*}{$\begin{array}{c}\sigma_{m} \\
(\mathrm{MPa})\end{array}$} & \multirow[b]{2}{*}{$n^{*}$} & \multirow{2}{*}{$\begin{array}{c}* * \\
H V\end{array}$} & \multicolumn{7}{|c|}{ Chemical composition (\% weight) } \\
\hline & & & & & $\mathrm{C}$ & $\mathrm{Si}$ & $\mathrm{Mn}$ & $\mathrm{Cr}$ & Mo & $\mathrm{Ni}$ & $\mathrm{V}$ \\
\hline $1-(420)$ & 350 & 630 & 0.24 & 200 & 0.38 & 0.9 & 0.5 & 13.6 & & & 0.3 \\
\hline $2-1045$ & 440 & 720 & 0.18 & 220 & 0.45 & $<0.4$ & 0.65 & & & & \\
\hline $3-3415$ & 460 & 590 & 0.14 & 210 & 0.14 & $<0.4$ & 0.55 & 0.75 & & 3.25 & \\
\hline $4-9255$ & 470 & 770 & 0.22 & 250 & 0.55 & 1.65 & 0.85 & & & & \\
\hline $5-4337$ & 920 & 1000 & 0.06 & 340 & 0.34 & $<0.4$ & 0.65 & 1.50 & 0.22 & 1.50 & \\
\hline
\end{tabular}

*Evaluated value for the whole interval of plastic strain (until fracture)

**Approximated value of micro-hardness obtained in the bulk material (after electrolytic polishing of the specimens)

TABLE 2-SHOT-PEENING PARAMETERS (ACCORDING TO MIL-S-13165 C)

\begin{tabular}{cccc}
$\begin{array}{c}\text { Peening } \\
\text { Medium }\end{array}$ & $\begin{array}{c}\text { Impact } \\
\text { Angle }\end{array}$ & $\begin{array}{c}\text { Almen } \\
\text { Intensity }\end{array}$ & Coverage \\
\hline S170 & $\pm 90^{\circ}$ & $14 \mathrm{~A}$ & $100 \%$
\end{tabular}

of hardness, the specimens were cut and their cross-sections were subjected to mechanical polishing. Micro-hardness indentations were made, from the surface to the interior of the bulk material, using a $100 \mathrm{~g}$ weight. A minimum distance to the surface, between 50 and $70 \mu \mathrm{m}$, was imposed to avoid edge effects on hardness readings.

For both types of specimen, $\mathrm{x}$-ray diffraction measurements were performed with the help of a standard $\Omega$ diffractometer using chromium radiation $(\mathrm{CrK} \alpha)$. The deformation of the Fe- $\alpha$ crystalline structure, corresponding to $\{211\}$ lattice planes, was analyzed, in both situations, using similar diffraction conditions. In the shot-peening specimens, the electrolytic removal technique was used for the study of in-depth evolution of $\mathrm{x}$-ray diffraction peak width (integral width), ${ }^{26}$ enabling the characterization of the strainhardening capacity of the shot-peened layers. In the tensile tests specimens, $x$-ray diffraction measurements were performed after unloading, i.e., after each plastic strain increment, until specimen fracture, allowing the evolution of the diffraction peak width with the plastic deformation to be studied. The diffraction peak width values obtained were related to the strain-hardening attained by the material during these tests.

\section{Experimental Results and Discussion}

\section{Interrupted Tensile Tests}

Figure 1 presents, as an example, the engineering stressstrain curves obtained in interrupted tensile tests for four steels listed in Table 1.

The corresponding true stress-plastic strain curves are shown in Fig. 2. These curves were obtained for the whole plastic strain interval, i.e., until the experimental point of fracture. Although it was determined, true stress was not corrected to take into account the effect of tri-axial stress state at the necked zone, an equation similar to eq (5) may be used for experimental data fitting. Thus, since true stress-plastic strain curves are known, hardness and diffraction peak width measured values, corresponding to given amounts of plastic strain, may be related to the yield strength.

As mentioned above, after each plastic strain increment of about $2 \%$, imposed during the tensile tests, shown in Fig. 1, hardness indentations and x-ray diffraction measurements were carried out on unloaded specimens. It was thus possible to analyze the evolution of hardness and diffraction peak width with the plastic strain. Figure 3 shows the experimental results.

The fitted curves shown in Fig. 3 correspond to the hardness variation (right axis) with the true plastic strain. Similar curves are obtained for diffraction peak width variation (left axis). In all cases, the hardness and integral width of the $\mathrm{x}$ ray diffraction peaks show the same tendency with increasing plastic strain, i.e., both can be fitted by using potential laws, like those represented by eq (4). As seen in Fig. 2, a similar behavior occurred in the case of the true stress-plastic strain relationship, which confirms the validity of eqs (4) and (5).

Knowing both the hardness-plastic strain curve (or diffraction peak width-plastic strain curve) and the true stress-plastic strain curve for each material enables the evolution of the hardness and diffraction peak width with the yield stress to be analyzed. Data fitting of the experimental results clearly shows that a linear law can be used to describe the evolution of hardness and diffraction peak width with the yield stress. Using bulk material reference values, for normalization proposes, as shown in Fig. 4, hardness relative variation and diffraction peak width relative variation can be considered proportional to yield stress relative variation. In Fig. 4, a bulk material yield stress value corresponding to $0.02 \%$ offset plastic strain was used for normalization proposes, in all cases;

It can be concluded that normalized hardness variation, or normalized diffraction peak width variation, can in themselves be considered a measure of the material's strain hardening, thus confirming the validity of the linearity hypothesis observed between the relative increments of hardness (diffraction peak width) and yield stress and, therefore, the validity of eqs (7) and (9), which are the basis of the proposed methodology. Thus, since experimental data confirm the validity of eq (9), if can be used to determine the material's yield stress, when it is subjected to a given level of plastic deformation, when the yield stress of the bulk material, the corresponding relative variation of hardness (or diffraction peak width) and the proportionality constant $\gamma$ are known.

The values obtained for the proportionality constant $\gamma$, which appears in eqs (7) and (9), corresponding to the normalized hardness variation and normalized diffraction peak width variation, respectively, are also indicated in Fig. 4 $(y=f(x)$ ). It can be seen that a similar behavior occurs for all studied materials.

In fact, the data fitting shown in Fig. 5, for the all materials studied, indicates a mean value of 2.8 for the proportionality constant $\gamma$ in the case of normalized hardness variation, and 1.01 in the case of normalized diffraction peak width 

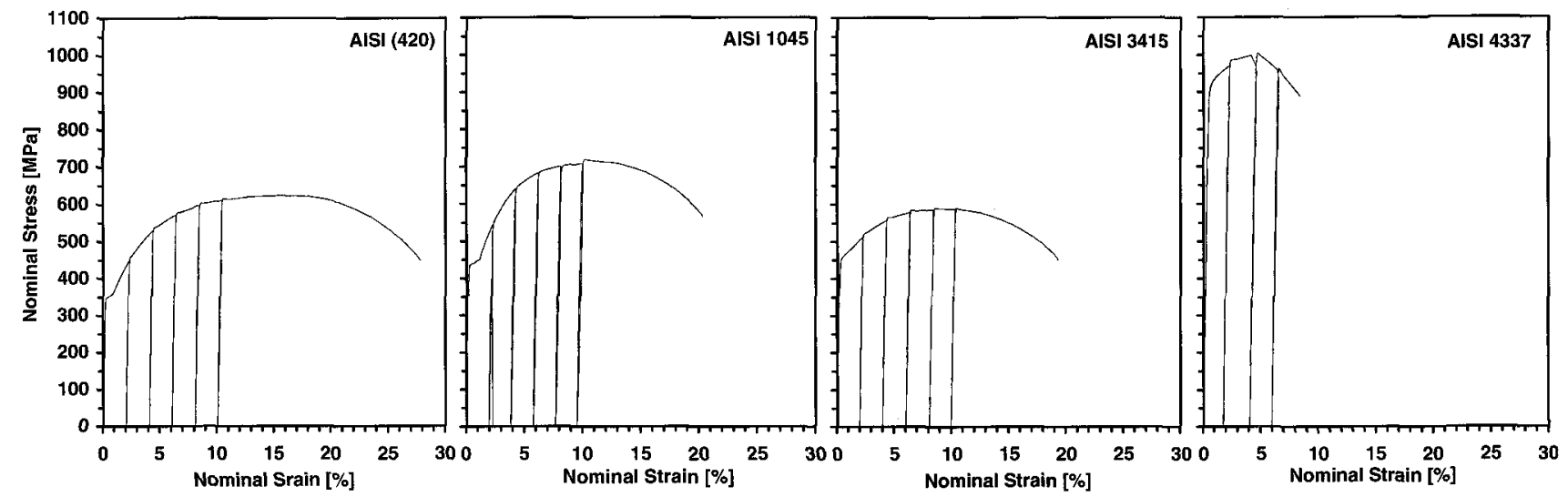

Fig. 1-Examples of nominal stress-strain curves obtained in the interrupted tensile tests
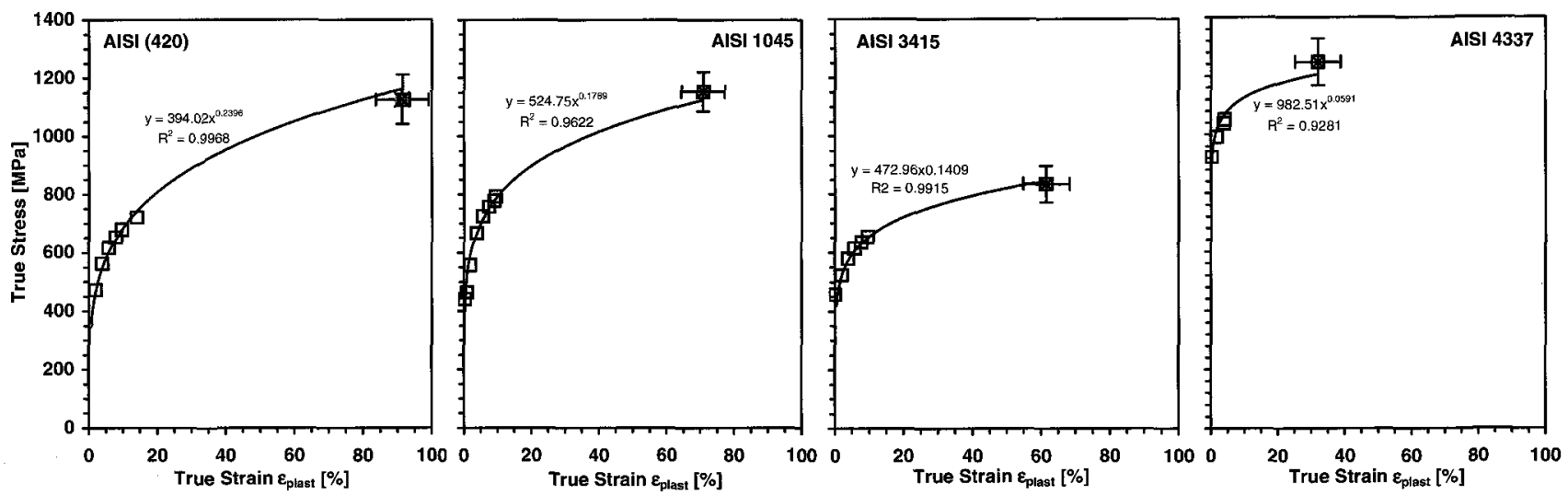

Fig. 2-Corresponding true stress-plastic strain curves; the marked point corresponds to material fracture
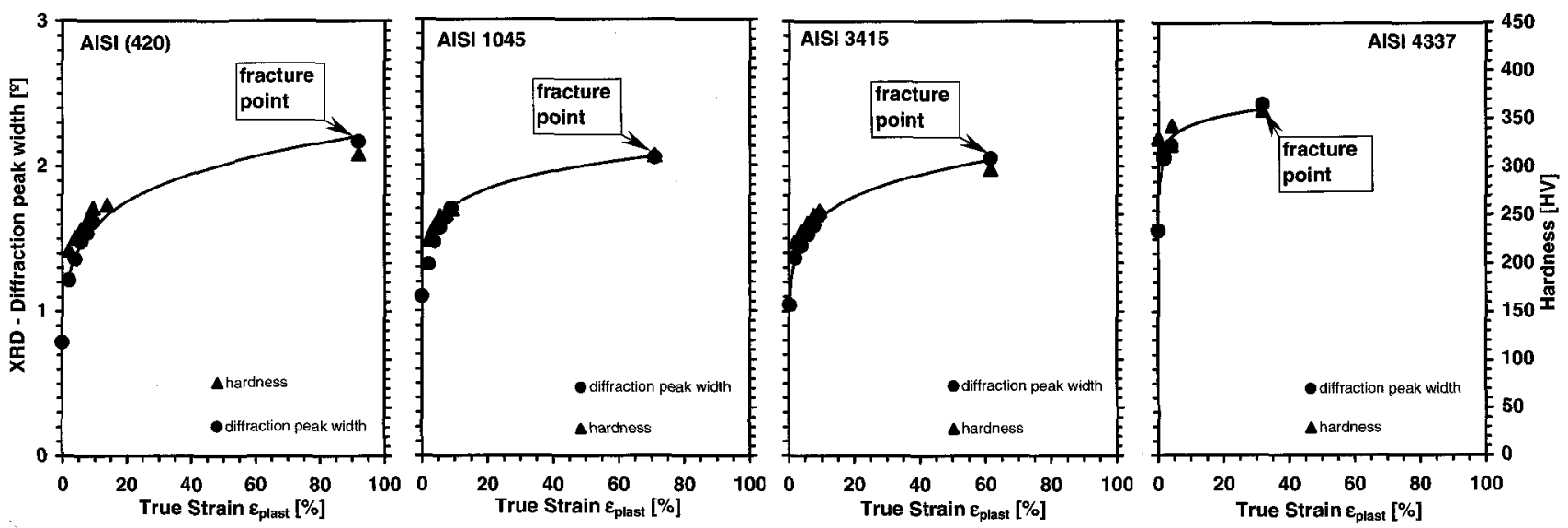

Fig. 3-Hardness and diffraction peak width as a function of true plastic strain

variation. That is, the interpolation of experimental data seems to indicate a direct proportionality between the relative increments of diffraction peak width and yield stress. The justification for this difference between the measuring methods could be related to the effect of the plastic deformation induced by the hardness indentation itself. Equivalent plastic strain, induced by a pyramidal indenter, is close to $8 \%$, and a relation of about 3 is found between the yield stress and the hardness of the material. ${ }^{14,18}$ This was also confirmed by our experimental data. In the case of $\mathrm{x}$-rays, the material is not disturbed by the measurement process itself, and therefore there exists a direct proportionality between normalized 

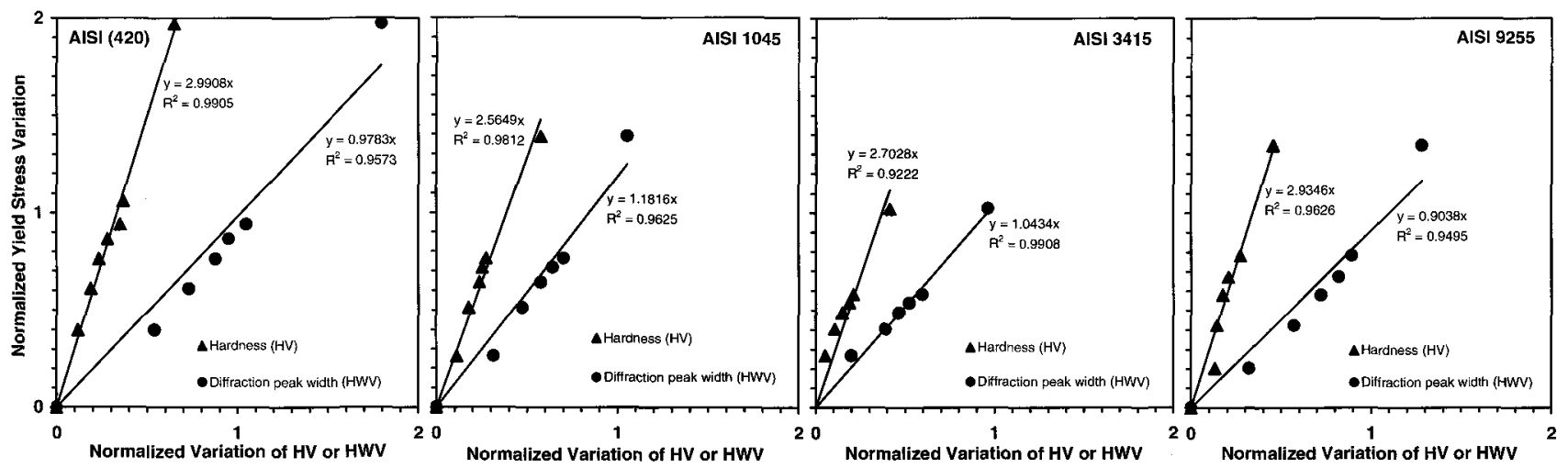

Fig. 4-Normalized variations of yield stress versus hardness $(H V)$ (or diffraction peak width $(H W V)$ )

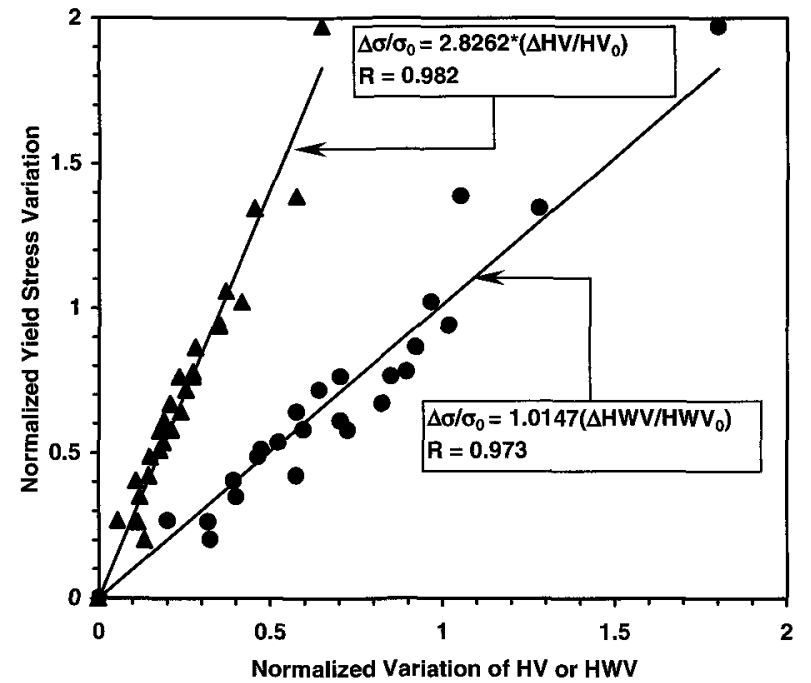

Fig. 5-Normalized variation of yield stress versus hardness $(H V)$ (or diffraction peak width $(H W V)$ ) for materials used in this study

yield stress variation and normalized diffraction peak width variation. In addition, this implies a difference in the sensitivity of the measuring methods. The diffraction method is more sensitive, but more difficult to perform, while the hardness method is less sensitive but much easier to perform.

For the steels studied, the proportionality constant $\gamma$ seems to be independent of the materials' strain-hardening behavior. That behavior could thus only be determined by knowing the normalized variation of hardness or diffraction peak width. This study should, however, be developed in the future and extended to another metals and alloys.

\section{Application of the Proposed Methodology: Estimation of a Local Yield Stress in Shot-Peened Surface Layers}

The empirical methodology described above will subsequently be used to evaluate the strain-hardening curves of materials and to estimate a local yield stress, as a function of the depth, in the surface layers affected by a similar shotpeening treatment, which was applied to several of the steel specimens listed in Table 1. The curves presented in Fig. 4 will be used as an experimental calibration, linking the normalized variations obtained during tensile tests with those obtained in shot-peened surface layers. This procedure will be used to estimate the yield stress throughout the whole treated depth.

Some observations should, however, be mentioned before the proposed methodology is applied to local yield stress estimation in shot-peened surface layers. First of all, the calibration procedure was obtained from uniaxial tensile tests. It is implicitly accepted that the material has a similar mechanical behavior in tension as it does in the case of compression loading. For materials which present deformation asymmetry in tension loading, compared with compression loading, as in the case of magnesium alloys, ${ }^{27}$ for example, this procedure requires caution, since yield strength in tension and compression is very different. However, relative to strain-hardening behavior, if differences arise, they should be reflected in the normalized hardness or diffraction peak width variation values obtained. On the other hand, it is well known that macrohardness or true hardness value is a material's constant and is traditionally related to the yield stress of the material under testing. The micro-hardness value, however, is no longer a material's constant, but depends on the indenter size, load and depth of indentation. ${ }^{24}$ This ISE is not well understood yet and it has been explained using various mechanisms. ${ }^{25}$ For the strain-hardening characterization of shot-peened surface layers, the lowest possible loads would be used for more localized Vickers micro-hardness readings and the ISE can therefore influence apparent hardness values. However, for the methodology proposed here, the use of the same load throughout the whole treated depth, regardless of its value, and the corresponding relative hardness variation values, can make the ISE negligible, since the normalized hardness variation itself is a measure of the strain-hardening attained by the treated material, as seen earlier. Finally, the direct effect of the residual stress state on micro-hardness readings should also be taken into account. In the case of tensile tests, no macro residual stresses arise after the specimen is unloaded, since the imposed plastic deformation can be considered uniform along the cross-sections of the specimens. In this case, micro-hardness readings are not affected by macro residual stresses, and therefore their variations, in a first approach, can be attributed to the strain-hardening effect. However, high compressive residual stresses induced by the shot-peening 

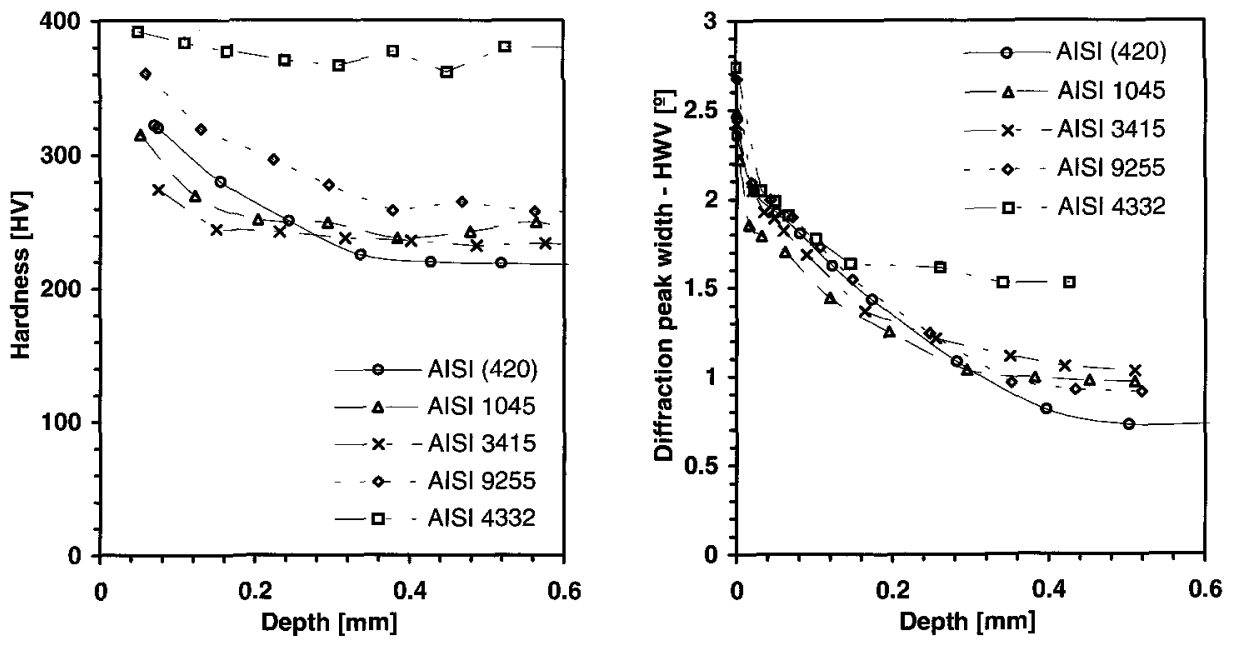

Fig. 6-Hardness and x-ray diffraction peak width profiles in shot-peened surface layers

treatment could have some influence on micro-hardness measurements. In a recent study on this issue,$^{28}$ a clear influence of residual stresses on hardness readings was confirmed. In that study, a bending bar, subjected to four-point bending, was plastically deformed up to $2 \%$ plastic strain. Measured hardness values, obtained during specimen's loading, clearly show dependency on the bending load. Decreasing hardness values, relative to the bulk material value, are observed on the tensile side and increasing hardness values are observed on the compressive side of the bar. After unloading, the residual stress state induces a similar behavior in hardness readings. This effect is, however, more pronounced in the tensile region. In the compressive region, the effect of the residual stresses on the hardness readings was not completely clarified and further studies should be performed, especially to clarify the combined effect of macro/micro residual stresses and the material's strain-hardening. Nevertheless, it should be remembered that the proposed methodology works with relative increments of hardness, which seem to be a direct measure of the strain-hardening effect. Furthermore, systematic errors in absolute hardness readings can also be reduced by using relative increment values. The importance of working with normalized hardness variation values seems, therefore, to be of great interest.

Figure 6 shows the in-depth evolution of hardness and diffraction peak width along the shot-peened surface layers. For all cases, both decrease continuously from the surface to the interior of the material, and therefore no signs of material softening at the surface seem to have occurred because of the shot-peening treatment, even in the case of the quenched and tempered steel (AISI 4332). On the other hand, it is clear that the greater strain-hardening capacity of the material, the higher are the normalized variation values attained, which confirms again that the normalized variations of hardness and diffraction peak width are a measure of the material's strain-hardening behavior.

For all cases, the material work-hardens at the surface. This being so, the normalized variation of hardness or diffraction peak width, obtained along the shot-peened layers, can be compared with that obtained from plastic deformation imposed in the tensile tests. Thus, taking into account the ex- perimental results presented in Figs. 4 and 5, which confirm the validity of eq (9), a local yield stress as a function of the treated depth can be estimated. Figure 7 presents the results obtained, showing that similar results are obtained no matter whether hardness or diffraction peak width data are used.

It should nevertheless be noted that, in the case of hardness data, if a direct calibration is performed using the absolute values from Figs. 2, 3 and 6, discrepancies occur between the hardness and diffraction peak width data, used for the local yield stress estimation, and erroneous results may arise. This is explained because specimen preparation procedures (cutting, mechanical polishing versus electrolytic polishing), used for hardness indentation measurements, affect the final results. A complementary study was carried out to evaluate the effect of the cutting procedure and mechanical polishing used for specimen preparation. Depending on the material, higher hardness values, between 15 and $20 H V$, were obtained for specimens subjected to cutting and mechanical polishing compared with those obtained for the specimens subjected to electrolytic polishing alone. Thus, since absolute hardness readings in the shot-peened surfaces are slightly higher than those obtained in the tensile specimen surfaces, due to the surface preparation, a consequent overestimation of estimated local yield stress is observed, compared with that obtained by using the diffraction peak width method. However, using relative variation data, this effect is avoided and similar results are obtained when either hardness or diffraction peak width data are used, as Fig. 7 shows. For the materials studied, similar local yield stress values were determined in the shotpeened layers using both methods. Therefore, the possible influence of residual stresses and/or ISE on the micro-hardness readings also seems to have been avoided somehow when normalized hardness variation data are used. Conversely, it could only be true if normalized hardness variation depends only on the material strain-hardening effect, which seems to be confirmed by our experimental results.

In Fig. 7, it can also be observed that the yield stress close to the surface attains values close to the material's fracture stress, which confirms that plastic deformation was very high. Moreover, in the layers near the surface, the material is subjected to few cycles of oligocyclic fatigue due to the impacts 

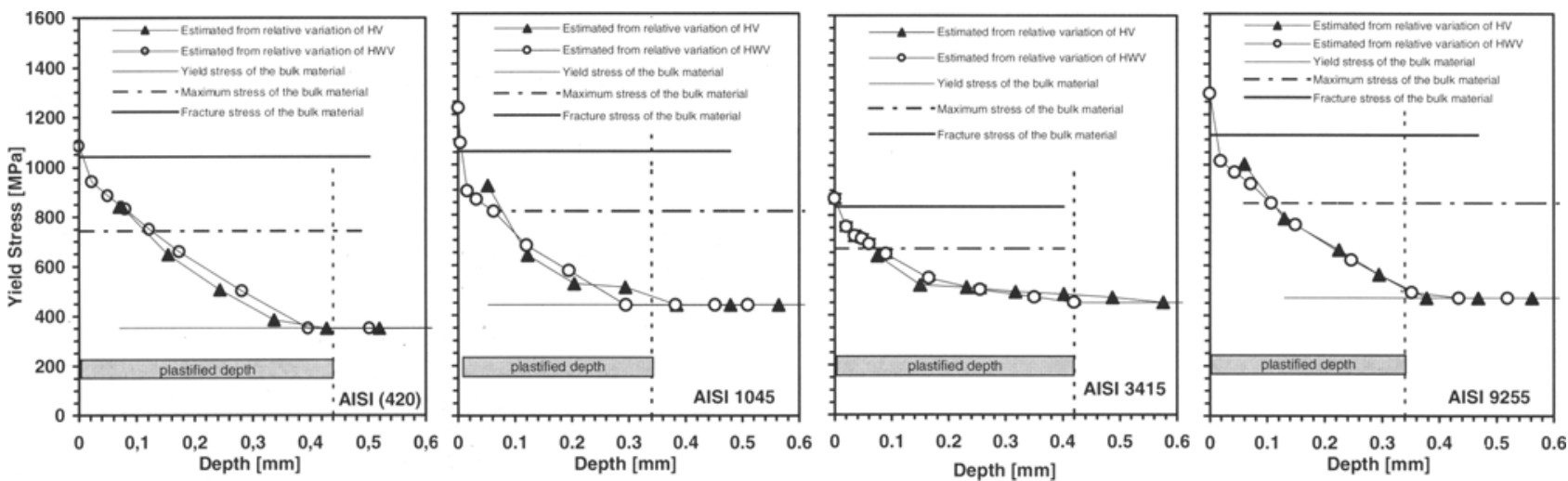

Fig. 7-In-depth estimation of local yield stress in shot-peened surface layers. Comparison between the results obtained using the normalized variations of hardness and $\mathrm{x}$-ray diffraction peak width

of the peening medium. Nevertheless, if stress-strain curves corresponding to the material near the surface (accommodated zone), exhibit a strain-hardening exponent close to that obtained for the bulk material, as suggested in a first approach in the method of Cao and Castex ${ }^{15}$ the proposed methodology can give reasonable estimates of the local yield strength throughout the whole shot-peened surface layer.

\section{Conclusions}

The experimental data obtained in five steels with differing mechanical properties, subjected to interrupted tensile tests, show that both the hardness variation and $\mathrm{x}$-ray diffraction peak width variation, with the plastic deformation, are related to the strain-hardening capacity of a material, with their normalized variations being proportional to the normalized variation of the material's yield stress. This experimental observation allows the following empirical equation to be obtained, which enables the yield stress of a material subjected to a given amount of plastic deformation to be determined, when the relative variation of hardness or diffraction peak width and the yield stress of the bulk material are known:

$$
\sigma_{y}=\sigma_{y, 0}\left(1+\gamma \frac{\Delta H}{H_{y, 0}}\right) .
$$

Here, the letter $H$ can correspond to hardness ( $H V$ ) or to diffraction peak width $(H W V), \sigma_{y, 0}$ and $H_{y, 0}$ correspond to the elastic limit and hardness (peak width) of the bulk material, respectively, and $\gamma$ is a constant. For the steels studied, the experimental results have shown that the value of this constant seems to be independent of the material's strainhardening, and a value close to 1 is obtained if the relative variation of diffraction peak width is used, while a value close to 2.8 is obtained, if the relative variation of hardness is used.

Taking into account the experimental results, an empirical methodology, based on the equation above, is proposed for the estimation of a mean local yield stress, as a function of the depth, in work-hardened surface layers. The estimation of the local yield stress, using the normalized variations of hardness and diffraction peak width, obtained in shot-peened surface layers, gives identical results, which seems to confirm the validity of the proposed methodology.

\section{Acknowledgments}

The authors gratefully acknowledge the financial support of Fundação para a Ciência e Tecnologia, FCT-Portugal, project POCTI/35953/EME/2000, which made this work possible.

\section{References}

1. Scholtes, B., "Eigenspannungen in Mechanisch Randschichtverformten Werkstoffzuständen: Ursachen, Ermittlung und Bewertung," Deutsche Gesellschaft fur Materialkunde-DGM Informationsgesellschaft $m b H$, Frankfurt (1991).

2. Nobre, J.P., Kornmeier, M., Dias, A.M., and Scholtes, B., "Use of the Hole-Drilling Method for Measuring Residual Stresses in Highly Stressed Shot-peened Surfaces," EXPERIMENTAL MECHANICS, 40 (3), 289-297 (2000).

3. Nobre, J.P., Kornmeier, M., Gibmeier, J., Dias, A.M., and Scholtes, B., "Plasticity Effect On Residual Stress Results Using Different Hole-Drilling Evaluation Methods," Proceedings of the 6th International Conference on Residual Stresses (ICRS6), Oxford, 10-12 July, Vol. 2, IOM communications, $1188-1195$ (2000).

4. Gibmeier, J., Kornmeier, M., and Scholtes, B., "Plastic Deformation during Application of the Hole-Drilling Method," 5th European Conference on Residual Stresses (ECRS 5), Delft, 28-30 September. A.J. Bottger et al., editors, Vol. 1, Trans Tech Publishers, 131-136 (1999).

5. Virmoux, P., Inglebert, G., and Gras, R., "Characterisation of ElastoPlastic Behaviour for Contact Purposes on Surface Hardened Materials," Dissipative Processes in Tribology, D. Downson et al., editors, Elsevier Science, Amsterdam, 287-301 (1994).

6. Batista, A., Dias, A., Virmoux, P., Inglebert, G., Le Flour, J., and Lebrun, J., "Characterisation of Mechanical Properties and Residual Stresses in Hardened Materials," Recent Advances in Experimental Mechanics, Proceedings of the 10th International Conference on Experimental Mechanics, Lisbon, 18-22 July, J. Gomes, editor, A. Balkema, 739-744 (1994).

7. Wohlfahrt, H., "The Influence of Peening Conditions on the Resulting Distribution of Residual Stress," Proceedings of the 2 nd International Conference on Shot Peening, Chicago, May 1984, SEM Ed, 316-331 (1984).

8. Desvignes, M., "Influence du Grenaillage de Précontrainte sur la Tenue en Fatigue de l'Acier 35CD4," Thesis: Docteur en Génie Mécanique, ENSAM, Paris (1987).

9. Cao, W., "Adoucissement Cyclique des Aciers et Relaxation des Contraintes Residuelles de Grenaillage en Fatigue," Thesis: Docteur en Génie Mécanique, ENSAM, Paris (1989).

10. Guechichi, H., "Prévision des Contraintes Résiduelles dues au Grenaillage de Précontrainte," Thesis: Docteur en Génie Mécanique, ENSAM, Paris (1986).

11. Ji, N. "Application de l'Analyse des Profils de Raies de Diffraction $X$ pour Caractériser L'État Microstructural et Mécanique des Matériaux Métalliques," Thesis: Docteur en Génie Mécanique, ENSAM, Paris (1989).

12. Maeder, G., Lebrun, J.L, and Sprauel, J.M., "Détermination par Diffraction des Rayons $X$ des Contraintes Internes: Aspects Macro e 
Microscopiques", in Physique et Mécanique de la Mise en Forme des Métaux, 2, ENSAM, Paris, 142-155 (1993).

13. Hakimi, D., "Caractérisation Mécanique et Métallurgique de la structure d'une Couche Grenaillée," Thesis: Thése de 3éme cycle, ENSAM, Paris (1984).

14. Tabor, D., "A Simple Theory of Static and Dynamic Hardness," Proceedings of the Royal Society London, Series A, 192, 247-274 (1948).

15. Cao, W. and Castex, L., "Determination of Stress-Strain Relation of the Shot-Peened Surface Layers with the help of X-Ray Diffraction HalfWidth," Metal Behaviour and Surface Engineering, B. Curioni et al., editors, Technology Transfer Series, 1, IITT-International, 309-314 (1989).

16. Zarka, J. and Casier, J., "Elastic-Plastic Response of a Structure to Cyclic Loading: Practical Rules," Mechanics Today, S. S. Nemat-Nasser editor, Vol. 6, Pergamon Press, New York, 93-198 (1979).

17. Batista, A. and Dias, A., "Characterization of Mechanical Properties in Surface-Treated Materials," Joumal of Testing and Evaluation, 28 (3), 217-223(2000)

18. Johnson, K.L., editor, "Contact Mechanics," Cambridge University Press, Cambridge (1985).

19. Studman, C.J., Moore, M.A., and Jones, S.E., "On the Correlation of Indentation Experiments," Journal of Physics D: Applied Physics, 10 (6), 949-956 (1977).

20. Elghazal, H., Dudragne, G., Girodin, D., Hamel, A., Lormand, G. and Vincent, A., "Etude du Comportment d'Aciers Cémentés Sollicités en Fatigue de Contact," Proceedings of the 17th Journées de Primtemps, Fatigue de Contact, Senlis, France, SFMM Ed., 27/1-27/12 (1998).
21. George, R.A., Dinda, S., and Kasper, A.S., "Estimating Yield Strength from Hardness Data," Metal Progress, 30-35 (May 1976).

22. Cahoon, J., Broughton, W., and Kutzak, A., "Determination of Yield Strength from Hardness Measurements," Metallurgical Transactions, 2, 1979-1983 (1971).

23. Lemaitre, J. and Chaboche, J.-L., "Mécanique des Matériaux Solides," Dunod, Paris (1985).

24. lost, A. and Bigot, R., "Reply 'Comment on Indentation Size Effect: Reality or Artifact?'," Joumal of Materials Science Letters, 17, 1889-1891 (1998).

25. 25. Gao, Y.X. and Fan, H., "A Micro-Mechanism Based Analysis for Size-Dependent Indentation Hardness," Journal of Materials Science, 37, 4493-4498 (2002).

26. François, M. et al., "X-Ray Diffraction Method," Handbook of Measurement of Residual Stresses, J. Lu, editor, Chapter 5, SEM, Bethel, 71-131 (1996).

27. Nobre, J., Noster, U., Gibmeier, J., Kornmeier, M., Dias, A., and Scholtes, B., "Mechanical Behavior and Residual Stresses in AZ31 Wrought Magnesium Alloy Subjected to Four-Point Bending," Mg Alloys and Their Applications, Munich, 26-28 September, K. Kainer, editor, Wiley-VCH, New York, 336-341 (2000).

28. Gibmeier, J. and Scholtes, B., "About the Effect of Residual Stresses on Micro-Hardness Readings," Proceedings of the 6ih European Conference on Residual Stresses, Coimbra, 10-12 July, A. Dias et al., editors, Vol. 404-407, Materials Science Forum, 349-354 (2002). 